\title{
Development of quality management in Taiwan the past, present and future
}

Chi-Kuang Chen, Iuan-Yuan Lu, Kuo-Ming Wang, Jiun-Yi Jang and Jens Jörn Dahlgaard

\author{
Linköping University Post Print
}

Tweet

N.B.: When citing this work, cite the original article.

This is an electronic version of an article published in:

Chi-Kuang Chen, Iuan-Yuan Lu, Kuo-Ming Wang, Jiun-Yi Jang and Jens Jörn Dahlgaard, Development of quality management in Taiwan the past, present and future, 2015, TOTAL QUALITY MANAGEMENT and BUSINESS EXCELLENCE, (26), 1-2.

TOTAL QUALITY MANAGEMENT and BUSINESS EXCELLENCE is available online at informaworldTM:

http://dx.doi.org/10.1080/14783363.2014.981071

Copyright: Taylor \& Francis (Routledge): SSH Titles http://www.routledge.com/

Postprint available at: Linköping University Electronic Press

http://urn.kb.se/resolve?urn=urn:nbn:se:liu:diva-113153 


\title{
Development of Quality Management in Taiwan The Past, Present and Future
}

\author{
*Chi-Kuang Chen
}

Professor, Department of Industrial Engineering \& Management, Yuan Ze University,

Taiwan, email: ieckchen@ saturn.yzu.edu.tw

\section{Iuan-Yuan Lu}

Chairman, Chinese Society for Quality; Professor, Department of Business

Management, National Sun Yat-Sen University, Taiwan, email:

iylu@bm.nsysu.edu.tw

\section{Kuo-Ming Wang}

Chair Professor, Department of Industrial Engineering \& Management, Yuan Ze

University, Taiwan, email: kmwang@saturn.yzu.edu.tw

\section{Jiun-Yi Jang}

Postdoc, Department of Industrial Engineering \& Management, Yuan Ze University, Taiwan, email: s968904@mail.yzu.edu.tw

\section{Jens J. Dahlgaard}

Professor, Department of Management and Engineering

Linköping University, Sweden, email: jens.jorn.dahlgaard@liu.se

\begin{abstract}
Quality Management (QM) has been popular and widely used in Taiwan since the 1960s. However, it is found that a review of its development is lacking. Hence, this paper aims to examine the history and the evolution of quality management in Taiwan, and to take a step further to look for the cues for shaping the future development. The research purpose of this paper is more specifically to review the development of quality management during the period from 1970 to 2012. 'Quality Magazine', the most popular reading materials on quality management in Taiwan, is selected as the search database.

The overall review result shows that the development of quality management in Taiwan has three developmental phases: (1) the quality technologies and tools focus period (1970-1985); (2) the quality management system integration period (1986-2000); (3) the quality in service industry development period (2001-2012).

In light of the overall as well as the detailed review results senior quality experts were invited for consultation, discussion and prediction of the needs and the future development of quality management in Taiwan.
\end{abstract}

Key words: Quality, Quality in Taiwan, Quality Management 


\section{INTRODUCTION}

Chinese Society for Quality (CSQ), which is the publisher of 'Quality Magazine', was established 50 years ago (1964), and has during the last 50 years played an important role in supporting its members by providing a wide range of activities, such as certification, training programs, publications and conferences. Today, CSQ is a global networking society with partner quality societies from around the world, including Asian Network for Quality (ANQ), American Society for Quality (ASQ), European Organization for Quality (EOQ), Union of Japanese Scientists \& Engineers (JUSE), and Chinese Excellent Management Association (CEMA).

Along with the thoughts placed in previous review research on the evolution of quality management (Ahire et al., 1993; Dahlgaard-Park et al., 2013) the objective of this paper is to provide a reflective review of the development of quality management in Taiwan. Our aim is to synthesize and organize knowledge from an industrial practice standpoint and offer suggestions for the needs and the future development of quality management in Taiwan.

We classify existing literature from the 'Quality Magazine' by number and the trend of articles published by topic and by industries. The total of 3162 articles published between January 1970 and December 2012 are then analyzed and a picture is taken from this review to represent the past, the trend and the current status of quality development in Taiwan. Finally, senior quality experts are invited to contribute with their insights of the needs and the future development of quality management.

\section{RESEARCH METHODS}

The steps of the research are described in the following. The first step was to conduct a retrospective analysis of the quality development in Taiwan based on articles published in the 'Quality Magazine'.

Quality Magazine was first launched in March 1965, and was titled 'Quality Control Newsletter' between 1965 and December 1968. The magazine changed the title to 'Quality Control Monthly' from January 1969 to April 2001, and was renamed again to 'Quality Monthly' in May 2001. For the reason of no electronic full texts and abstracts being collected in the database before 1970, we collected only articles published between January 1970 and December 2012 in this research. A total of 3162 articles were identified which include 1298 articles in 'Quality Control Monthly' and 1864 articles in 'Quality Monthly'. Table I presents the number of articles being collected in each period. 
Table I Total number of articles published in the Quality Magazine (1970-2012)

\begin{tabular}{cccc}
\hline Year & 1970(January)-2001 (April) & 2001(May)-2012 & Total \\
\hline \# of articles & $1298(41 \%)$ & $1864(59 \%)$ & $3162(100 \%)$ \\
\hline
\end{tabular}

In the second step, the articles were classified into the following terms of topics: 'quality concepts \& core values', 'quality systems \& management' and 'quality techniques \& methods'; industries between 'manufacturing industry' and 'service industry', and service industries among 'education', 'public service' and 'health care' (see Table II). Trend analyses were performed to investigate the development and progress, and to draw out a picture from the retrospection to represent the current status of quality development in Taiwan.

Table II List of classification scheme

\begin{tabular}{|c|c|}
\hline $\begin{array}{l}\text { Classification by } \\
\text { topics }\end{array}$ & $\begin{array}{l}\text { 1. quality concepts \& core value } \\
\text { 2. quality systems } \& \text { management } \\
\text { 3. quality techniques \& methods }\end{array}$ \\
\hline $\begin{array}{l}\text { Classification by } \\
\text { industries }\end{array}$ & $\begin{array}{l}\text { 1. manufacturing industry } \\
\text { 2. service industry }\end{array}$ \\
\hline $\begin{array}{l}\text { Classification by } \\
\text { service industries }\end{array}$ & $\begin{array}{l}\text { 1. education } \\
\text { 2. public service } \\
\text { 3. health care } \\
\end{array}$ \\
\hline
\end{tabular}

In the third step, content analysis (Anderson et al., 2007) was conducted to further investigate the developmental trends. Content analyses from the quality management literature are among others Ahire et al. (1995), Sila \& Ebrahimpour (2002); Rahman \& Sohal (2002).

\section{REVIEW FROM 1970 THROUGH 2012}

\section{Summary of annual publications}

Table III presents the number of articles published annually from 1970 through 2012. The total number of articles published during this period was 3162, and 2002 had the largest number of articles (220 articles). 
Table III Annual distributions of the papers published in the Quality Magazine

\begin{tabular}{cccccccc}
\hline Year & \# of articles & Year & \# of articles & Year & \# of articles & Year & \# of articles \\
\hline 1970 & $38(1 \%)$ & 1981 & $18(1 \%)$ & 1992 & $30(1 \%)$ & 2003 & $205(6 \%)$ \\
1971 & $45(1 \%)$ & 1982 & $44(1 \%)$ & 1993 & $46(1 \%)$ & 2004 & $219(7 \%)$ \\
1972 & $36(1 \%)$ & 1983 & $39(1 \%)$ & 1994 & $48(2 \%)$ & 2005 & $202(6 \%)$ \\
1973 & $29(1 \%)$ & 1984 & $36(1 \%)$ & 1995 & $46(1 \%)$ & 2006 & $213(7 \%)$ \\
1974 & $30(1 \%)$ & 1985 & $48(2 \%)$ & 1996 & $64(2 \%)$ & 2007 & $191(6 \%)$ \\
1975 & $19(1 \%)$ & 1986 & $44(1 \%)$ & 1997 & $49(2 \%)$ & 2008 & $149(5 \%)$ \\
1976 & $30(1 \%)$ & 1987 & $33(1 \%)$ & 1998 & $46(1 \%)$ & 2009 & $97(3 \%)$ \\
1977 & $19(1 \%)$ & 1988 & $46(1 \%)$ & 1999 & $78(2 \%)$ & 2010 & $90(3 \%)$ \\
1978 & $49(2 \%)$ & 1989 & $43(1 \%)$ & 2000 & $47(1 \%)$ & 2011 & $113(4 \%)$ \\
1979 & $50(2 \%)$ & 1990 & $40(1 \%)$ & 2001 & $103(3 \%)$ & 2012 & $104(3 \%)$ \\
1980 & $45(1 \%)$ & 1991 & $21(1 \%)$ & 2002 & $220(7 \%)$ & Total & $3,162(100 \%)$ \\
\hline
\end{tabular}

Figure 1 presents the frequency chart from which it can be seen that the articles published during 1970-2000 kept a steady-low trend followed by a significant increase in the period 2000 to 2002, and then a decline after 2002.

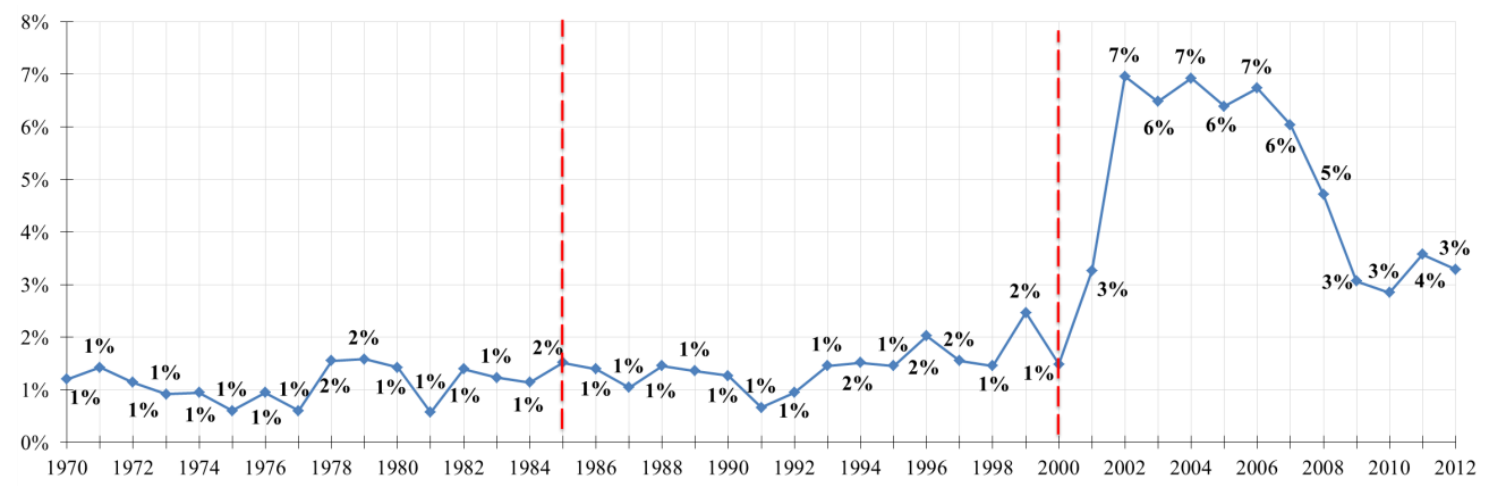

Figure 1 Frequency chart for the articles published in each year (1970-2012)

Regarding this trend information, three periods are identified (Table IV). The first period is the early publications, started from 1970-1985 (575 articles), the second is the mid-period publications during 1986-2000 (681 articles), and the third period is the recent publications in 2000 and onwards (1906 articles).

Table IV Number of articles published in three stages (1970-2012)

\begin{tabular}{clc}
\hline Year & \multicolumn{1}{c}{ Period } & \# of articles (\%) \\
\hline $1970-1985$ & Early publications & $575(18 \%)$ \\
$1986-2000$ & Mid-period publications & $681(22 \%)$ \\
$2001-2012$ & Recent publications & $1906(60 \%)$ \\
\hline
\end{tabular}




\section{Classification by topics}

Table $\mathrm{V}$ presents the distribution of the articles classified by topics in the three categories 'quality concepts \& core values', 'quality systems \& management' and 'quality techniques \& methods'.

Table V Distribution of articles by topics (1970-2012)

\begin{tabular}{cccccc}
\hline Year & $\begin{array}{c}\text { Quality } \\
\text { Concepts \& } \\
\text { Core Value } \\
(\boldsymbol{\%})\end{array}$ & $\begin{array}{c}\text { Quality } \\
\text { System \& } \\
\text { Management } \\
(\boldsymbol{\%})\end{array}$ & $\begin{array}{c}\text { Quality } \\
\text { Techniques } \\
\text { \& Methods } \\
(\boldsymbol{\%})\end{array}$ & $\begin{array}{c}\text { Others } \\
(\boldsymbol{\%})\end{array}$ & Total (\%) \\
\hline $1970-1985$ & $78(15 \%)$ & $79(15 \%)$ & $343(65 \%)$ & $24(5 \%)$ & $524(100 \%)$ \\
$1986-2000$ & $104(14 \%)$ & $387(52 \%)$ & $170(23 \%)$ & $78(11 \%)$ & $739(100 \%)$ \\
$2001-2012$ & $245(13 \%)$ & $1,539(81 \%)$ & $77(4 \%)$ & $38(2 \%)$ & $1,899(100 \%)$ \\
Total & 427 & 2005 & 590 & 140 & 3162 \\
\hline
\end{tabular}

In the period of 1970-1985, the largest number of published articles were 'quality techniques \& methods'; the number of articles in this category was 343 which is $65 \%$ of the total number of articles published in this period. In the period of 1986-2000, the largest number of published articles was in the 'quality system \& management' category; the number of articles in this category was 387 (52\%). In the period of 2001 to 2012, the largest amount of published articles were also in the 'quality system \& management' category; the number of articles in this category was 1539 (81\%). The number of published articles in the category of 'quality concepts \& core value' was the least among three categories during the periods 1970-1985 and 1986-2000. The number of articles was 78 (15\%) and 104 (14\%) respectively. It is interesting to find that the number of published articles in the 'quality concepts \& core value' category has increased during the period of 2001-2012.

Figure 2 shows the trend of articles by topics in the three categories. The trends show different shapes. The trend of 'quality systems \& management' is steeply increasing over time while the trend of 'quality concepts \& core value' is relatively constant. The trend of 'quality techniques \& methods' decreases over time. 


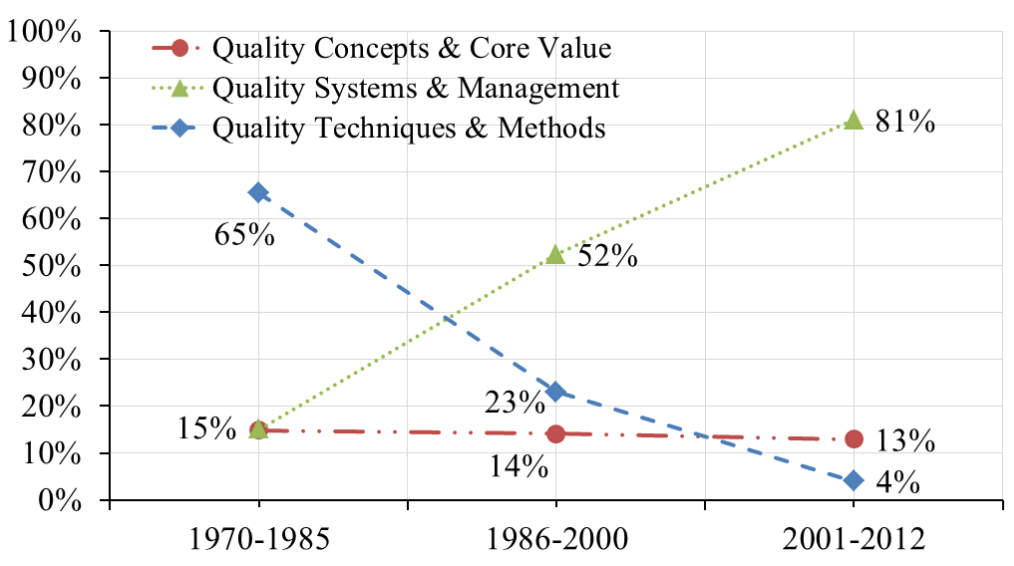

Figure 2 Distributions of classification articles published in three topics

(1970-2012)

\section{Classification by industries}

Table VI presents the distribution of the articles classified in 'manufacturing industry' and 'service industry'.

Table VI Distribution of articles by industries (1970-2012)

\begin{tabular}{cccc}
\hline Year & Manufacturing (\%) & Service (\%) & Total (\%) \\
\hline $1970-1985$ & $363(96 \%)$ & $14(4 \%)$ & $377(100 \%)$ \\
$1986-2000$ & $318(70 \%)$ & $138(30 \%)$ & $456(100 \%)$ \\
$2001-2012$ & $443(47 \%)$ & $498(53 \%)$ & $941(100 \%)$ \\
Total & 1124 & 650 & 1774 \\
\hline
\end{tabular}

In the period of 1970-1985, it can be seen that the percentage of published articles in the 'manufacturing industry' (96\%) was much higher than 'service industry' (4\%). In the period of 1986-2000 the gap between the two groups became less, and the percentage of articles in the two categories was $70 \%$ and $30 \%$ respectively. In the period of 2001-2012, the percentage of published articles in 'manufacturing industry' (47\%) became less than 'service industry' (53\%).

Figure 3 shows the trend of classified articles by the two categories of industries. The trends show different shapes. The trend of 'service industry' publications is steeply increasing over time, whereas, it is decreasing over time in the 'manufacturing industry'. 


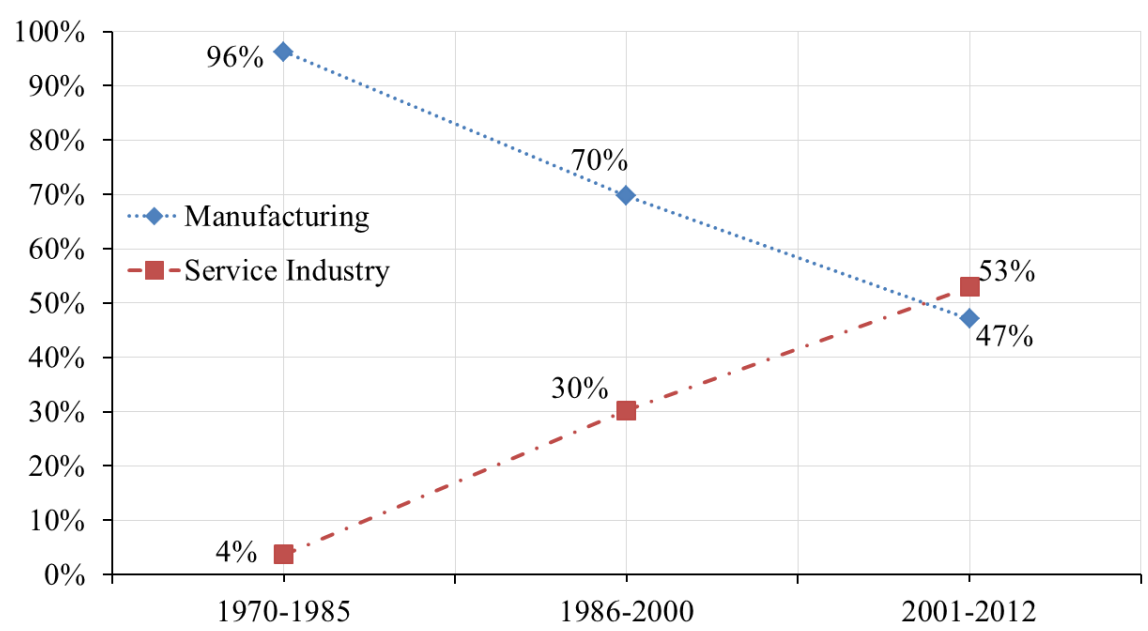

Figure 3 Distributions for the articles published in manufacturing and service industries (1970-2012)

\section{Classification by service industries}

Table VII presents the distribution of the 'quality in service' articles classified into the following three categories: 'education', 'public service' and 'health care'. It can be seen that the total number of articles in the three categories were 118, 107 and 86 respectively, and the number of published articles increases significantly over time for each category.

Table VII Distribution of article by service industries (1970-2012)

\begin{tabular}{ccccc}
\hline & Education & Public service & Health care & Total \\
\hline $1970-1985$ & 0 & 9 & 0 & 9 \\
$1986-2000$ & 21 & 35 & 12 & 68 \\
$2001-2012$ & 97 & 63 & 74 & 234 \\
Total & 118 & 107 & 86 & 311 \\
\hline
\end{tabular}

Figure 4 shows that the three service industry categories each has a steep increase over time. The 'public service' trend showed a linear increase, while the trends showed an accelerated increase over time in the categories of 'education' and 'health care'. 


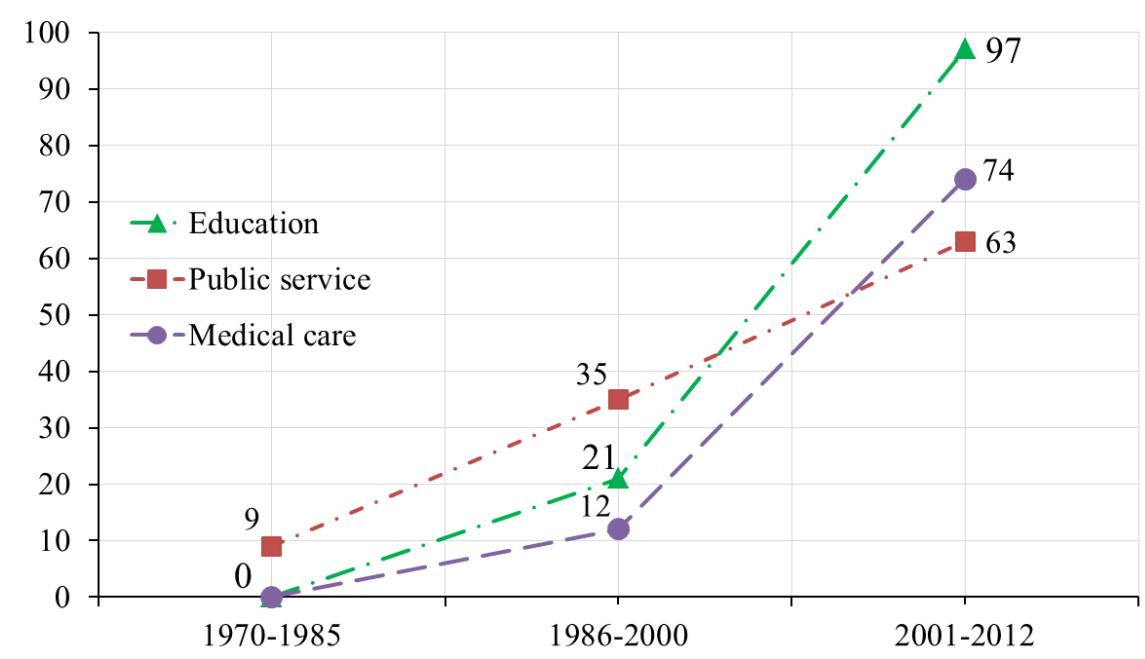

Figure 4 Distributions of for the articles published in education, public service and health care (1970-2012)

\section{DEVELOPMENT OF QUALITY MANAGEMENT IN TAIWAN}

In light of the above review, it can be concluded that quality management principles, tools and methods have been widely used in Taiwan for about half a century. In particular, since 2000 the term 'Taiwanese quality' has become popular in the management literature as well as in the business world.

Based upon the research findings discussed above we define the following three development phases for the quality management development in Taiwan: 1970-1985 'quality technologies and tools focus period'; 1986-2000 'quality management system integration period'; 2001-2012 'quality in service industry development period'. We will in the following go a step further to investigate the evidences supporting each of the three development phases.

\section{Quality technologies and tools focus period (1970-1985)}

Based on above review we found that the published articles in this period focused mainly on quality techniques $\&$ methods.

Through a content analysis of the 343 published articles the five most popular quality techniques \& methods were identified as: statistical process control (SPC), quality control circles (QCC), sampling inspection (SI), design of experiments (DOE), and reliability analysis (RA). Table VIII presents the results of content analyses of the five quality techniques $\&$ methods.

In the 'statistical process control' methods category the following four article themes were found: 'control charts', 'process capability index $\left(\mathrm{C}_{\mathrm{p}} \mathrm{k}\right)$ ', 'correlation analysis', and 'regression analysis/ prediction' method. It was found that each theme was actively practiced during this period, and some of the articles recorded how these 
quality techniques and methods were practiced in Taiwanese industries during the 1960s.

Table VIII Article themes in quality techniques \& methods (1970-1985)

\begin{tabular}{|c|c|}
\hline Topics & Article theme \\
\hline Statistical Process Control & $\begin{array}{l}\text { - } \text { control chart } \\
\text { - } \text { process capability index }\left(\mathrm{C}_{\mathrm{p}} \mathrm{k}\right) \\
\text { - } \text { correlation analysis } \\
\text { - } \text { regression analysis/prediction method }\end{array}$ \\
\hline Quality Control Circles & $\begin{array}{l}\text { - seven QC tools } \\
\text { - QC story } \\
\text { - PDCA management cycle } \\
\end{array}$ \\
\hline Sampling Inspection & $\begin{array}{l}\text { - } \text { sampling inspection } \\
\text { - } \text { probability sampling theory } \\
\text { - } \text { sampling plan } \\
\end{array}$ \\
\hline Design of Experiments & $\begin{array}{l}\text { - } \text { Taguchi method } \\
\text { - analysis of variance (ANOVA) } \\
\text { - } \text { signal noise (SN) ratio } \\
\end{array}$ \\
\hline Reliability Analysis & $\begin{array}{l}\text { - } \text { reliability test } \\
\text { - failure mode \& effect analysis (FMEA) } \\
\text { - fault tree analysis (FTA) }\end{array}$ \\
\hline
\end{tabular}

In the 'quality control circle' methods category the following three article themes were found: 'seven QC tools', 'QC story' and 'PDCA management cycle'. It was found that most of the published articles around the three themes were about the issues in regard of QCC implementation, QCC presentation, and the notes of Japanese factory tours on learning QCC. QCC was introduced to Taiwan from Japan in the mid-1960s, and Taiwan was one of the earliest QCC adoption counties in the world. The first QCC was established in 1967, and the QCC method has stayed popular until now. The first article by Chung (1970) discussed the advantages of QCC and showed the benefits of practicing QCC such as reducing production costs and improving product value.

In the 'sampling inspection' methods category the following three article themes were found; 'sampling inspection', 'probability sampling theory', and 'sampling plans'. It was found that most of the articles published around the three themes discussed the approaches in regards to sampling procedures, the decision making of sampling and the correction action plan. As both SPC and sampling inspection are two of the cornerstones of quality control these methods may play very important roles in enhancing product quality when thoroughly implemented. In particular, these methods were crucial for Taiwanese industries when they developed into an export-oriented economy.

In the 'design of experiments (DOE)' methods category the following three 
article themes were found: 'Taguchi method', 'analysis of variance (ANOVA)' and 'signal noise (SN) ratio'. Among the three article themes most published articles concentrated on coaching how to use design-of-experiment approaches such as applications within new product development \& design, optimization of quality characteristics in production engineering, etc. It is interesting that one article, written by Wu (1970), presented the notes of Dr. Taguchi's Taiwan visit, which indicates that Taiwan adopted Japanese quality methods soon after their development and release in Japan. We know that many Japanese quality experts such as Dr. Taguchi were invited to Taiwan in that period to coach in applying these methods.

In the 'reliability analysis' methods category the following three article themes were found: 'reliability test', 'failure mode \& effect analysis (FMEA)', and 'fault tree analysis (FTA)'. These methods are becoming more and more important because the quality concept has moved from a focus on production processes to a product design focus. Among the three article themes most articles discussed topics around the introduction of reliability, the system reliability testing approach, and the reliability in quality design. Particularly the methods were widely used in the electronics industry.

\section{Quality management system integration period (1986-2000)}

During the period of 1986-2000, it was found that the most discussed topics in 'Quality Magazine' were about quality management systems such as 'ISO 9000 \& ISO 14000 certification', and 'quality awards \& business excellence'. These topics contributed to the integration of quality techniques \& methods into a holistic quality management system. Through a content analysis of the 387 published articles from this period the following three most popular quality management systems methods were identified: quality certification (QC), total quality management (TQM), and National Quality Award (NQA)/Business Excellence (BE). Table IX shows the results of content analyses of the three quality management system methods.

Table IX Article theme and authors in the quality management system (1986-2000)

\begin{tabular}{cl}
\hline Topics & \multicolumn{1}{c}{ Article theme } \\
\hline \multirow{3}{*}{ Quality Certification } & - ISO 14000 certification \\
& - qSO 9000 certification \\
& - 8 D Process \\
Total Quality Management & - Total Productive Maintenance (TPM) \\
& - Toyota Production System (TPS) \\
& - 6-sigma \\
\hline \multirow{2}{*}{ National Quality } & - Business Excellence Model (BEM) \\
Award/Business Excellence & - Maiwan National Quality Award (TNQA) \\
& (MBNQA) \\
\hline
\end{tabular}


In 'quality certification' systems category the following three article themes were found: 'ISO 14000 certification', 'ISO 9000 certification' and 'quality audit'. It was found that most of the articles around these three themes were about guidance of quality certification, experience sharing of ISO practices, and cause-and-effect relationships between ISO practice and business performance. Chen (1994) made a comparison of total quality control and ISO 9000 certification to help industries to integrate both systems further in a holistic way. Furthermore, it was found that ISO certifications were widely used in various industries such as the construction industry.

In the 'total quality management' systems category the following four article themes were found: '8D Processes, 'Total Productive Maintenance (TPM)', 'Toyota Production System (TPS)', and 'six-sigma quality'. In light of the published articles we are convinced that industry performance grew significantly due to good practice of these quality management systems. Lu (1998) conducted a case study to investigate the roadmap for successfully practicing total quality management.

In the 'National Quality Award/ Business Excellence' systems category the following three article themes were found: 'business excellence models (BEM)', 'Taiwan National Quality Award (TNQA)' and 'Malcolm Baldrige National Quality Award (MBNQA)'. Among these three articles themes most articles discussed topics such as guidance of Taiwanese National Quality Award (TNQA) application, the implementation of NQA to enhance business performance, and the cultivation of organization culture toward business excellence.

TNQA was established in 1989, and at that time it was one of the earliest countries in the world to inaugurate NQA. In order to promote business excellence all the winners were invited to join an association called 'CEMA' which is a cross-industry benchmark platform for pursuing excellent quality management. Chen (2000) investigated cause-and-effect relationships between the enablers and business results of implementing excellence models. The results indicated that organizations which successfully had implemented TNQA obtained significant benefits including financial profit as well as non-financial outcomes.

To complement the three topics stated above, we know that the quality management system initiatives are implemented in achieving the continuous improvement and benchmarking. It is impossible to accomplish this objective without the culture of total acceptance and involvement by employees and performing on a daily basis. The lack of the right culture will result in practitioners keeping away from the management approach. In the period of 2001-2012, we found a number of published articles dealing with such issues, which include 'leadership', 'employee involvement', 'delight the customer' and 'continuous improvement'. 
Quality in service industry development period (2001-2012)

Service sciences have become a fast growing discipline during the past two decades. Based on the information shown in Figure 3, we found that the focus had shifted from manufacturing to service during the period of 2001-2012. The number of published articles related to service exceeded the number of articles related to manufacturing, and it seems that this new trend or phenomenon will continue to increase in importance.

Through content analysis of the 498 published articles from this period we found the following four most popular topics on service development: service industry, service quality, services science, and service innovation. Table $\mathrm{X}$ presents the results of content analyses of these four topics.

Table X Article theme and authors in the service industry development (2001-2012)

\begin{tabular}{cl}
\hline Topics & \multicolumn{1}{c}{ Article theme } \\
\hline \multirow{3}{*}{ Service industry } & - education \\
& - public service \\
& - health care \\
& - KANO model industry \\
\hline \multirow{3}{*}{ Service quality } & - SERVQUAL \\
& - PZB gap model \\
\hline \multirow{3}{*}{ Services science } & - service system \\
& - experiential marketing \\
& - service provider \\
& - TRIZ \\
& - value chain \\
Service innovation & - innovation process \\
& - patent \\
& - service design \\
\hline
\end{tabular}

In the topic of 'service industry' the following four article themes were found: 'education', 'public service', 'health care' and 'food industry'. Among these four article themes, it was found that most of the articles were related to topics such as guidance of practicing quality management including the implementation of service recovery to enhance performance, the specific concerns of service quality in each service industry etc.

In the topic of 'service quality the following three article themes were identified: 'KANO model', 'SERVQUAL' and 'PZB gap model'. In light of the huge number of articles related to these three themes it is obvious that quality of services has become one of the most popular issues in Taiwanese service industries.

In the topics of 'service science' the following four article themes were identified: 
'service system', 'experiential marketing', service provider' and 'customer service'. Among these four themes most of the articles concentrate on how to use service science to enhance service quality and business performance in service industries including the introduction of service science, the recent development on service science, service science management and engineering (SSME), etc. One article, which was writtern by $\mathrm{Wu}$ (2009), discussed the practices of SSME in the service industry.

In the topics of 'service innovation' the following five article themes were found: 'TRIZ', 'value chain', 'innovation process', 'patent' and 'service design'. Among these five themes most of published articles concentrate on how to use service innovation in service industries including also the methodologies of service innovation, the use of the value chain concept and approach in service designs, etc. In particular, the service design for aging people has become one of the most popular issues being dealt with under this topic.

\section{SUGGESTIONS FOR THE FUTURE DEVELOPMENT}

In light of the review results presented in the previous sections a consultation meeting has been set up to discuss the future needs and development of quality management in Taiwan. The most senior quality experts in Taiwan were invited to participate in this meeting including the chairmen and board members of Chinese Society for Quality (CSQ) and Chinese Institute of Industrial Engineers (CIIE), which are the two most important quality professional societies in Taiwan.

The consultation meeting was conducted in the following way. First, the review results of this research project were sent to the experts one week before the meeting together with an invitation to attend a face-to-face meeting to brainstorm on key issues related to the needs and future development of quality management in Taiwan. The experts' comments were recorded on tapes and transcribed into a written script for content analysis. Based on the results of the content analysis four key issues were identified as discussed below.

The first and the most important issue raised by the senior experts was that the organizational culture of quality is still an issue that is not been practiced very well in Taiwanese industries. This issue was also indicated from the content analysis of the published articles discussed above where it was found that the topics of quality concepts \& core values have been increasing in the recent period. The prescription given by senior experts to remedy this issue was to focus more on development of practical approaches in order to cultivate the right organizational quality culture.

The next key issue raised by the senior experts is that quality has to be treated as a strategic management tool instead of just an operational methodology or technique for improvements of product quality. In their opinion, conducting quality practices 
should not only have a long-term consideration but it should also integrate quality activities into daily operations. This means that using quality practice as part of the strategic planning process should also be aligned with other organizational systems linking with performance and involving staff in the daily operations. It is coincident with previous literature, such as for example Garvin (1988) argued that lack of strategic planning is a major drawback or hindrance for implementation of quality improvement initiatives. In respond to this issue, the senior experts suggested that it is necessary to develop guidance for organizations to link strategy planning with the routine levels of quality operations.

The third key issue raised by the senior experts was that organizations are still weak in building performance measurement systems for quality practices. In their opinions, the scope of quality practice doesn't just include quality techniques and methods but should cover all activities in the business. That means it has to take into account both the short-term operation and the long-term strategic planning; also it has to consider the performances in both enablers and results of the excellence models used. In addition, they believe that this will become even further important due to the growing popularity of quality practices in service industries during the past decade. The senior experts suggested that the challenges and remedies will be placed onto the adjustment and modification of the existing quality management system and the integration of quality tools and techniques to fit with the needs of the new-born service industries.

The fourth key issue raised by the senior experts was about the quality practices in global supply chain management. Based on their opinions, the global business environment has been increasingly difficult for firms to cope with and to sustain competitive advantages by using their own efforts only, and as a result, collaboration and alliances between independent firms are now growing into the so-called global supply chain management. As it was also found through the literature analysis that quality management systems in the whole global supply chain are still few, the senior experts suggested that the issue of quality management in the context of supply chain management deserves to receive more attention including the development of a roadmap for implementing TQM in supply chain management.

\section{REFERENCES}

Ahire, S. L., Landeros, R. \& Golhar, D. Y. (1995), Total Quality Management: A literature review and an agenda for future research, Production and Operations Management, 4(3), 277-306.

Anderson, J. L., Jolly, L. D. \& Fairhurst, A. E. (2007), Customer relationship management in retailing: A content analysis of retail trade journals, Journal of Retailing and Consumer Services, 14(6), 394-399.

Chen, Y. S. (1994), The complimentary role of TQC and ISO 9000, Quality Control Monthly, 30(5), 48-49. 
Chen, C. K. (2000), Investigating the advantages of winning Natioal Quality Awards, Quality Control Monthly, 36(12), 41-42.

Chung, C. C. (1970), Introduction of QCC practices, Quality Control Monthly, 6(11),8-9.

Dahlgaard-Park, S. M., Chen, C. K., Jang, J. Y. \& Dahlgaard, J.J. (2013), Diagnosing and prognosticating the quality movement: a review on the 25 years quality literature (1987-2011), Total Quality Management \& Business Excellence, 24(1\&2), 1-18.

Garvin, D. A. (1988), Managing Quality: The Strategic and Competitive Edge, New York: The Free Press.

Lu, D. (1998), Success of TQM: The findings from case study and survey, Quality Control Monthly, 34(9), 69-71.

Rahman, S. \& Sohal, A. S. (2002), A review and classification of total quality management research in Australia and an agenda for future research, International Journal of Quality \& Reliability anagement, 19(1), 26-4.

Sila, I., \& Ebrahimpour, M. (2002), An investigation of the total quality management survey based research published between 1989 and 2000: a literature review, International Journal of Quality \& Reliability Management, 19(7), 902-970.

$\mathrm{Wu}$, H. H. (2009), Development of service science, management and engineering, Quality Monthly, 30(7), 29-32.

Wu, Y. (1970), A note for Dr. Taugchi visit Taiwan, Quality Control Monthly, 5(2), $1-3$. 